\title{
Erratum: A small molecule modulates Jumonji histone demethylase activity and selectively inhibits cancer growth
}

Lei Wang, Jianjun Chang, Diana Varghese, Michael Dellinger, Subodh Kumar, Anne M. Best, Julio Ruiz,

Richard Bruick, Samuel Penã-Llopis, Junjie Xu, David J. Babinski, Doug E. Frantz, Rolf A. Brekken, Amy M. Quinn, Anton Simeonov, Johnny Easmon \& Elisabeth D. Martinez

Nature Communications 4:2035 doi: 10.1038/ncomms3035 (2013); Published 24 Jun 2013; Updated 22 Oct 2013

This Article contains errors in Figs 4 and 6 that were introduced during the production process. In Fig. 4d, the lane labels 'HA-JMJD2B mut' and 'HA-JMJD2B' on the western blot were inadvertently switched. In Fig. 6b,c, labels for the red and green lines were also accidentally swapped. Correct versions of both figures appear below.
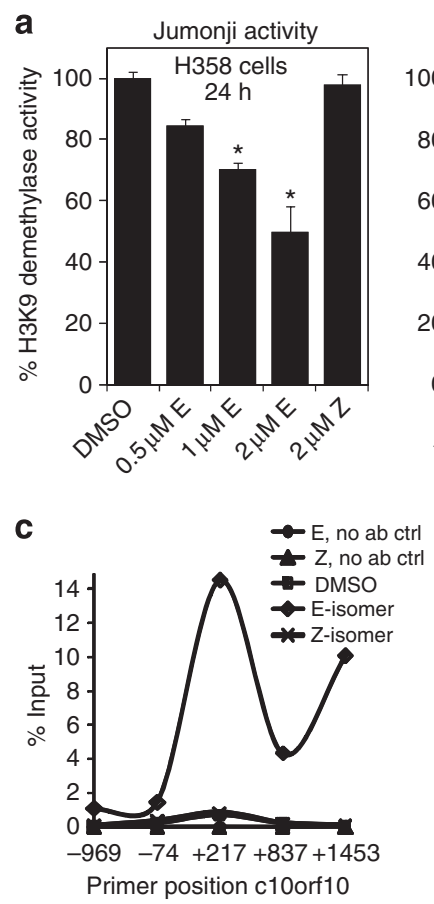

Figure 4 b
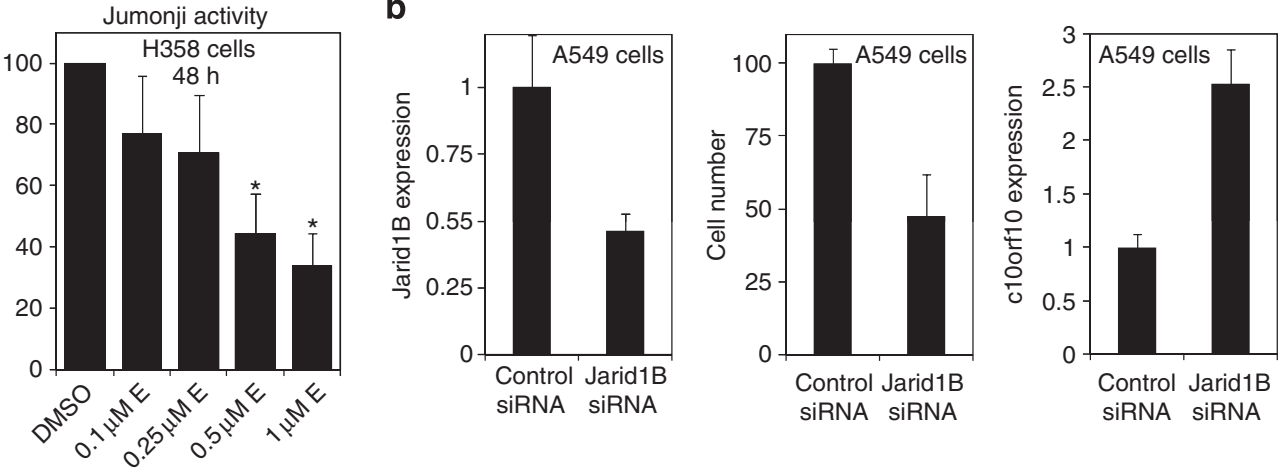

d
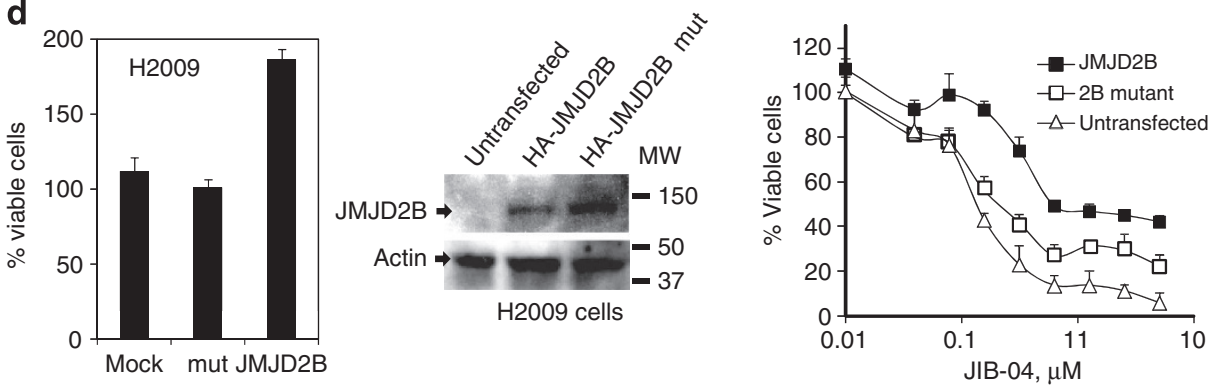

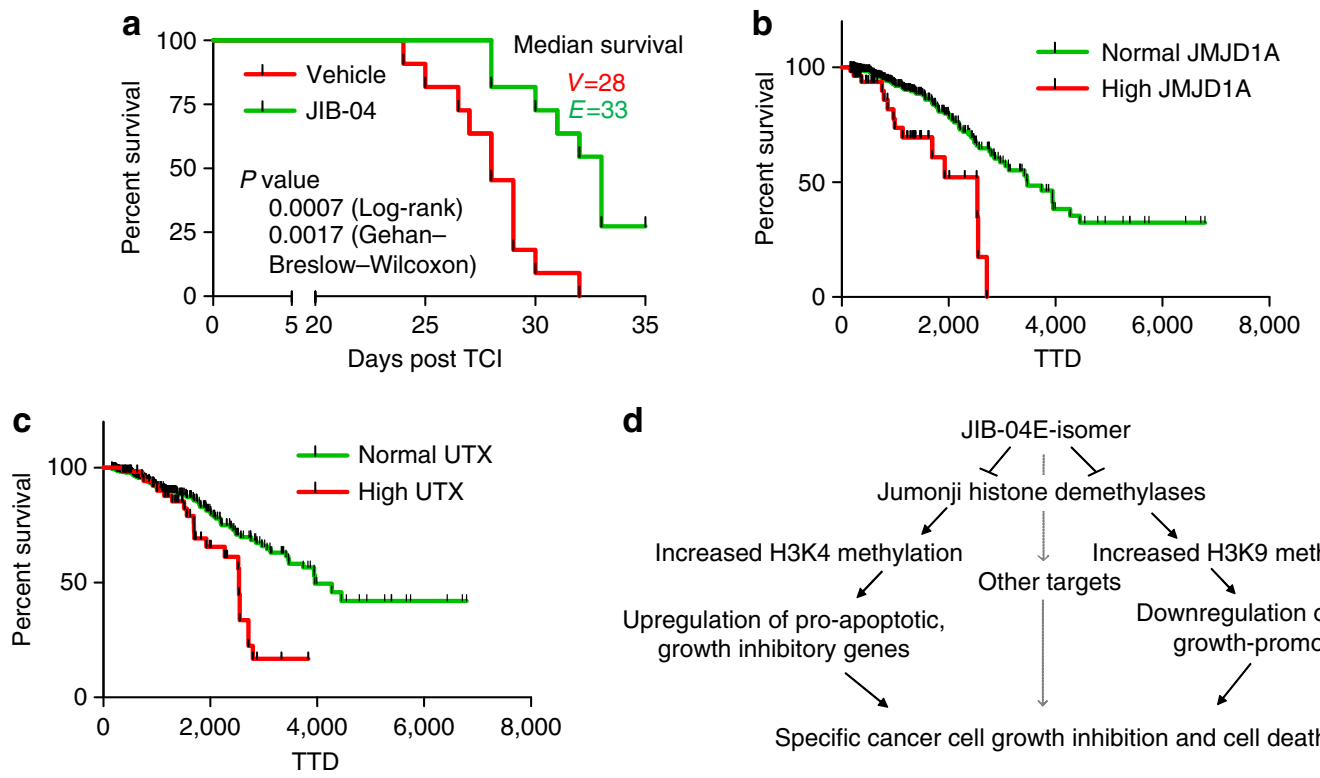

d

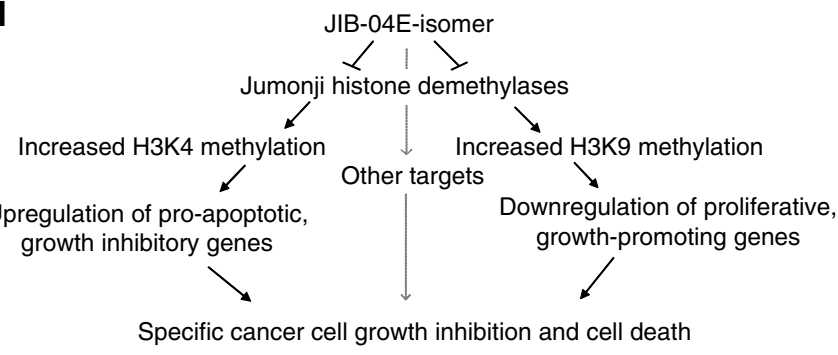

Figure 6 